\title{
AC 2009-647: GRADUATE CERTIFICATE IN TECHNOLOGY ENTREPRENEURSHIP: NEW BUSINESS OPPORTUNITIES FOR ENGINEERS, SCIENTISTS, AND BUSINESS STUDENTS
}

\section{Jorge delosRios-Hurtado, Texas Tech}

Jorge delosRios-Hurtado is a second-year student in the M.S program in Systems and Engineering Management at Texas Tech University. He received his B.S. in Industrial Engineering from the University of Lima in Peru. His research interests include engineering and technological entrepreneurship and management. He has two years of work experience in production areas in both pharmaceutical and dairy and food companies. He has also had an internship in a well-known Peruvian oil company that has a joint venture with Oiltanking, one of the world's leading independent storage partners for oils, chemicals, and gases.

\section{David Wyrick, Texas Tech}

David A. Wyrick, Ph.D., P.E., is Professor and Bryan Pearce Bagley Regents Chair of Engineering at Texas Tech University. His research interests include effective management of technology, small and medium enterprises, and entrepreneurial engineering. He teaches courses in engineering entrepreneurship, decision theory, and innovation and intellectual property. Prior to coming to TTU, he was professor and head of the Department of Mechanical and Industrial Engineering at the University of Minnesota Duluth. He serves on the board of directors for the American Society for Engineering Management. 


\title{
Graduate Certificate in Technology Entrepreneurship: New Business Opportunities for Engineers, Scientists, and Business Students
}

\begin{abstract}
This paper describes the design of an Interdisciplinary Graduate Certificate in Technology Entrepreneurship at Texas Tech University (TTU). This graduate certificate was designed for students who would like to develop a cross-disciplinary perspective in technology using both engineering and business skills. We based this certificate on a previous Undergraduate Certificate in Technology Entrepreneurship that is jointly delivered by the Edward E. Whitacre Jr. College of Engineering and the Rawls College of Business Administration. We believe that a Graduate Certificate in Technology Entrepreneurship is the logic next level needed to promote entrepreneurial spirit. We analyzed all graduate courses offered from the colleges of Architecture, Arts and Sciences, Engineering, Agricultural Sciences and Natural Resources, and Business and designed a 12 credit-hour graduate certificate. These courses provide tools, objectives, case studies, strategies, and business plan developments, so every willing student can apply them to develop new opportunities at any entrepreneurial level. This study introduces a cross-campus certificate model that utilizes an interdisciplinary approach to education and will prepare TTU students to succeed in technology-driven industries.
\end{abstract}

\section{Introduction}

The value of goods and services that new and small businesses in the United States produce and the new jobs they generate make this sector one of the greatest economic powers in the world, accounting for millions of dollars of commerce annually. Nowadays, it seems that the economic deceleration that affecting the whole world is also affecting small businesses. It is essential for all Americans to continue generating new ideas and opportunities in order to generate new ventures. The Edward E. Whitacre Jr. College of Engineering and the Rawls College of Business Administration realized that TTU students needed to understand and learn about what entrepreneurship is all about.

For this reason, since 2006 these two colleges have been working together to develop mechanisms for both undergraduate and graduate students to learn core entrepreneurship principles. They developed a dual Business/Engineering undergraduate Certificate in Technology Entrepreneurship ${ }^{1}$. This Certificate (coupled with a B.S. in Engineering or a Bachelor of Business Administration) was based on three courses requiring a total of 9 credit hours, as shown below. 
- Required Business Foundation Course for Engineering Students:

- BA 3302, Financial and Managerial Accounting

- Required Engineering Foundation Course for Business Students:

- IE 4320, Fundamentals of Systems

- Required Courses for All Certificate Program Students:

- MGT 4376, Entrepreneurship II: Discovering Entrepreneurial Opportunity

- IE 4331 Individual Studies in Industrial Engineering: Engineering Entrepreneurship

Also, the area of Management at the Rawls College of Business Administration (COBA) is developing an Entrepreneurship and Family Business Program that utilizes two sequential foundation courses (Entrepreneurship Creation and Entrepreneurship Discovery) to prepare students to exploit any three additional courses as the "practice ground", and to generate actionable opportunities regardless of their major or career settings, be it in sciences, biology, business, engineering, medicine, architecture, or some other field.

The purpose for offering graduate certificates in entrepreneurship is to meet the supplemental education needs of professionals. As jobs and job-related responsibilities change, a person often needs additional training in a specific area. For example, an engineer who once thought he or she would design new bridges may become involved in economic problems. If this engineer had not taken any basic financial for non-business students or entrepreneurship courses for the primary degree, a graduate certificate in technology entrepreneurship would provide needed knowledge. Providing graduate certificates for workforce development is a high priority for the Texas Higher Education Coordinating Board, which oversees all post-secondary education in the State of Texas.

A graduate certificate program is a set of courses that provides in-depth knowledge in a subject matter. The knowledge in this set of courses should provide a coherent knowledge base, even if the courses are selected from more than one academic program. The set of courses may be more practice-oriented than the set of courses in a graduate academic program. A graduate certificate program generally will be made up of no fewer than 12 hours and no more than 15 hours of graduate courses. All graduate certificate programs will follow the rules and regulations of the Texas Higher Education Coordinating Board.

Moreover, all those initiatives mentioned will help us to build up this graduate certificate in technology entrepreneurship, and to develop a cross-campus entrepreneurship model. Most technological programs are not designed to increase student's ability in state-of-the-art product creation and development techniques. This model will create new options for graduate students who want to create, innovate and discover new business opportunities. 
To develop this graduate certificate, we decided to create a model that represents what we wanted to illustrate. Since we utilized the interdisciplinary approach to entrepreneurship education, we needed to select business related courses from all the colleges that were involved. We needed a model that could interconnect all these courses and colleges (Architecture, Arts and Sciences, Engineering, Agricultural Sciences and Natural Resources, and Business) in one entrepreneurship frame. This paper will show how we integrated a model where basically every college is involved. It will also show some results from an on-line survey where students were asked about their program preferences, entrepreneurial ideas, and exposure to new venture opportunities.

\section{Previous Work on Interdisciplinary Studies}

According to Drucker ${ }^{2}$, business educators and professionals have evolved beyond the myth that entrepreneurs are born, not made, and it has nothing to do with the genes. It is a discipline. And, like any discipline, entrepreneurship can be learned. Solomon, Duffy, and Tarabishy ${ }^{3}$ concluded that pedagogy is changing based on a broadening market interest in entrepreneurial education.

New interdisciplinary programs use faculty teams to develop programs for non-business students, and there is a growing trend in courses specifically designed for art, engineering, and science students. Technologies are changing requirements in engineering design and product creation $^{4}$. Early research focused on measuring the achievement motive among students regarded as having high- and low-entrepreneurial orientations. Sagie and Elizur ${ }^{5}$ found differences among four achievement components tested with small-business students tending to score higher than their business and economics counterparts.

The University of North Dakota states that building cross-campus partnerships consists of three phases $^{6}$. The first phase is to establish an entrepreneurship certificate program for undergraduate majors. (The undergraduate certificate at Texas Tech can be considered in this first phase for a cross-campus initiative.) Then, phase 2 establishes a cognate in new product development for graduate non-business majors. Finally, phase 3 establishes new, fully-integrated joint programs in entrepreneurship. This three-phase project seems very similar with our approach. Nevertheless, UND focuses their phases on non-business majors. We believe that both nonbusiness and business majors need to be involved in a cross-campus initiative.

St. Mary's University developed an undergraduate cross-course project model ${ }^{7}$. Nonetheless, they only focused their study on two courses that might be part of their project. Their result was a guideline that incorporates lessons of what to do right and correct what can go wrong throughout the cross-course project experience. Then, Penn State University ${ }^{8}$ designed and developed a multidisciplinary course that pairs business and engineering students on teams with the objective of developing a new small product. Again, we find repeatedly that many universities are developing multidisciplinary courses instead of multidisciplinary certificates. 
The University of Texas at Austin also possesses an interdisciplinary course cross-listed in the School of Business, the College of Natural Sciences, the School of Law, and the College of Engineering ${ }^{9}$. In this interdisciplinary course, students develop skills in commercialization of specific technologies. This interdisciplinary course, as many others shown in our literature search, makes possible a cross-campus entrepreneurship initiative.

Vickers ${ }^{10}$ presents results of an online survey where he identified forty-eight graduate certificates with elements of entrepreneurship on thirty-seven U.S. institutions. However, only fifteen out of those forty-eight graduate certificates were technology driven certificates. As we can see, it is surprising to find the lack of interdisciplinary graduate certificates in technology entrepreneurship. TTU wants to develop a Graduate Technology Entrepreneurship Certificate (GTEC) to prepare graduate to either enhance their current business abilities, or explore starting a new company.

\section{Certificate Structure}

The purpose of this Graduate Technology Entrepreneurship Certificate (GTEC) is to prepare graduate students in architecture, sciences, engineering, agricultural sciences and natural resources, and business careers in technology-driven industries (See Figure 1). The certificate program is designed for those students who would like to develop a cross-disciplinary perspective of technology using both engineering and business skills. This GTEC will contain four courses (12 credit-hours). Three of them will be selected from the management and the industrial engineering departments. The fourth one will be a business-related course selected by the student from a set of courses already assign by the program.

\section{Figure 1: Colleges involved in Graduate Certificate}

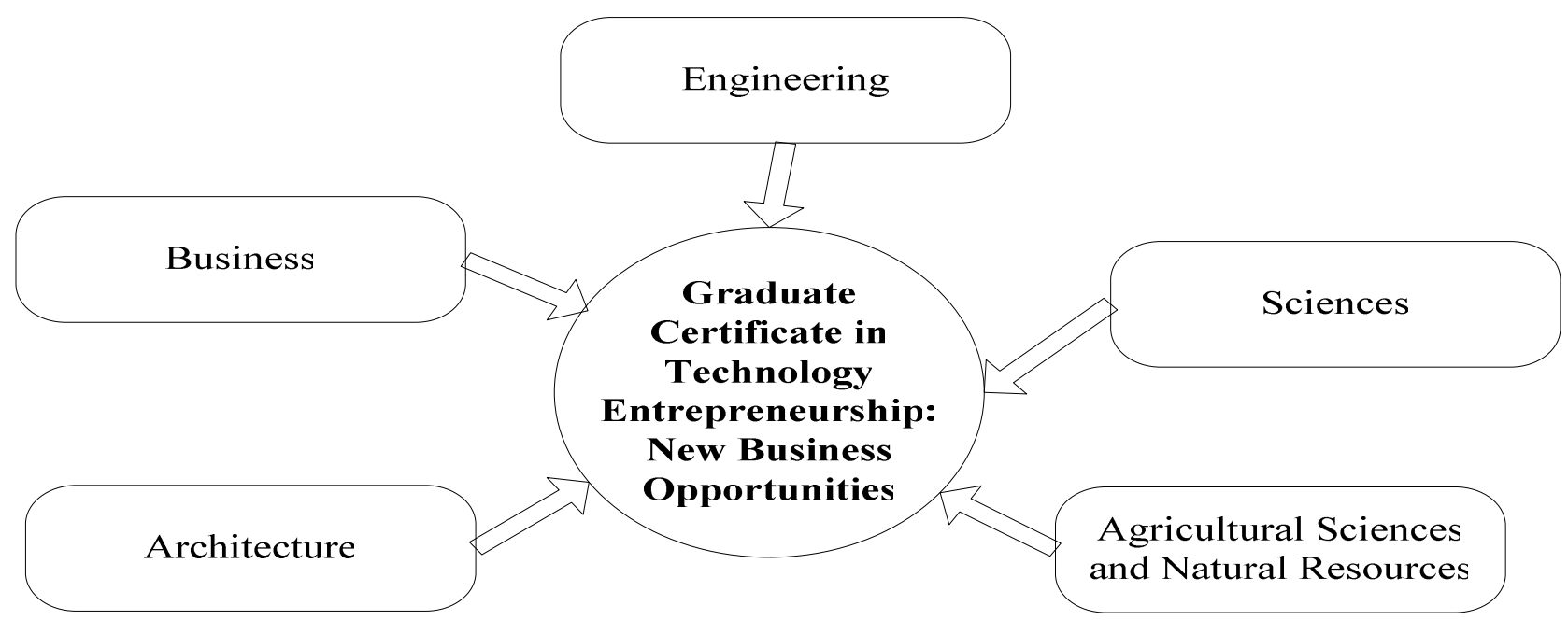


To illustrate the structure of our certificate, we created the "Wind Turbine Model ${ }^{\mathrm{TM}}$ " (Figure 2). As one can see, the structure of the model consists of three blades and one generator. The generator is the unit of the wind turbine that transforms mechanical energy into electrical energy. The blades transfer the kinetic energy from the wind into rotational energy in the transmission system, and the generator is the next step in the supply of energy from the wind turbine to the electrical grid ${ }^{11}$. This same effect is we wanted to convey with our certificate.

Figure 2: The Wind Turbine Model ${ }^{\mathrm{TM}}$

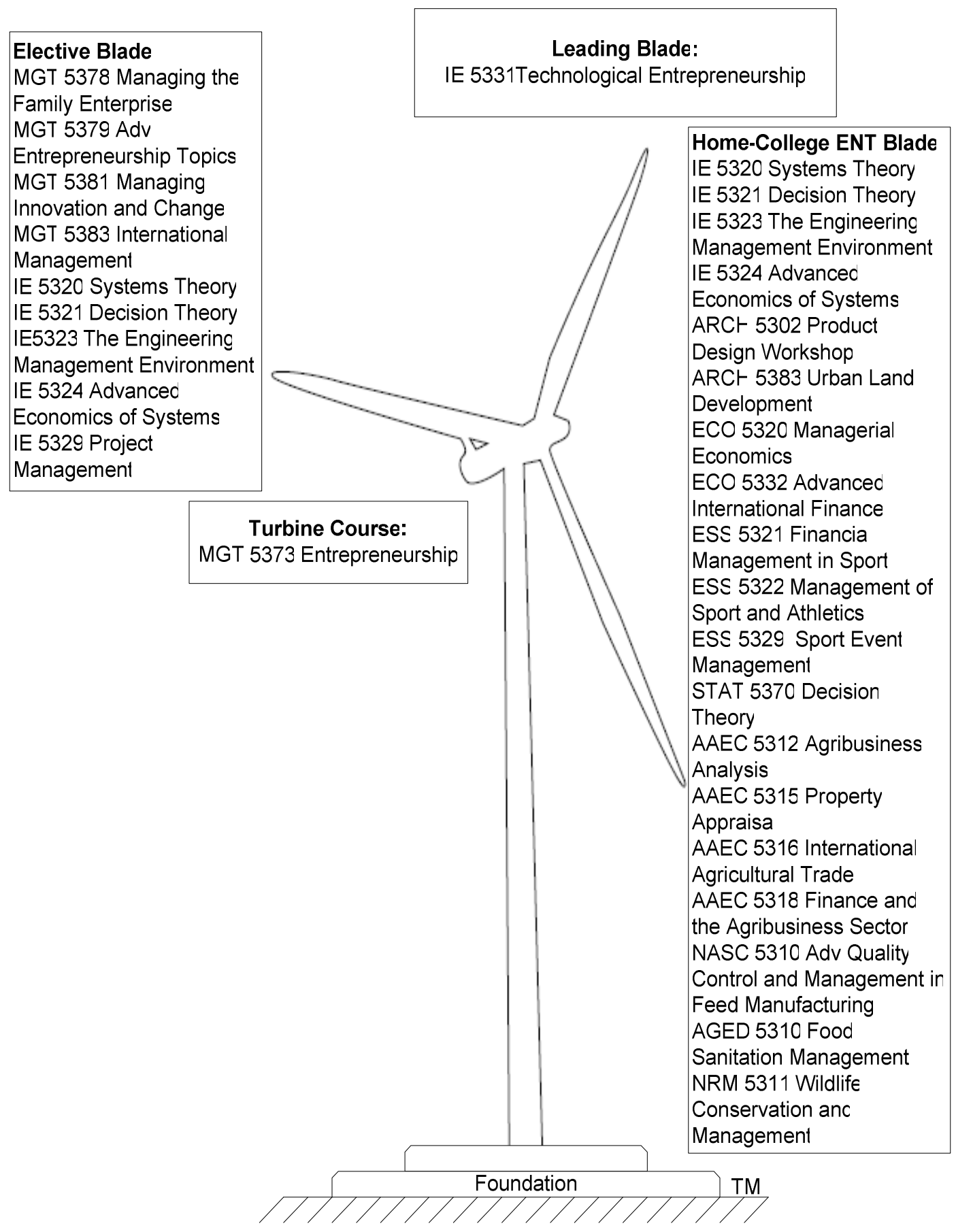


We knew we needed one course that could transform all that energy available from the students into real entrepreneurship knowledge. As a result, our first step was to identify that single course (turbine course) that could give us all the tools required to develop this idea, the generator idea.

Then, we needed to have courses to support our model (See appendix 1 for details). So, we place them on the three blades that the wind turbine possesses. The first blade we called it "Leading Blade". Since this blade will create a technological entrepreneurship vision to all students, we wanted to have an engineering course as a second requirement for this certificate. The second blade will be called "Elective Blade". This blade will content courses from either the Management and the Systems and Engineering Management curricula. Students will be able to select one course from either department.

Finally, the last blade is called the "Home-College Blade". This blade will provide flexibility to our certificate. We understand that sometimes graduate students prefer not to take courses from other departments, so they can finish their degree more rapidly. However, we also know that a graduate certificate can be very important for any student. For this reason, we wanted to give all the students enrolled in this GTEC the opportunity to take courses from their own curricula where they can utilize entrepreneurial thinking, and receive course credit for their degree programs. We first defined business-related courses as the courses that possess managerial, financial, marketing, or accountancy approaches that would generate and develop entrepreneurial thinking among TTU students. Then, we analyzed all the courses from the college of Agricultural Sciences and Natural Resources, Architecture, Sciences, Engineering, and Business in order to set this blade.

Figure 2 also shows how we applied a wind turbine generator to our GTEC. We believe that this original model will provide the knowledge, opportunities, and flexibility to all graduate students at Texas Tech University. It is important to note that the courses shown for the "Home-College Blade" are not an exhaustive list of all the business-related courses identified, but is a sampling in the interest of space for this paper.

\section{Cross Campus Survey}

The Department of Industrial Engineering at the Edward E. Whitacre Jr. College of Engineering has developed a survey to identify what students think about entrepreneurship and creation of business opportunities. It was essential to conduct this survey to determine levels of interest among the university's interdisciplinary population. Following the goal of assessing the level of interest in new ventures and new venture courses across all university areas, we identified three important research questions: 
1. To what extent do students across the university population think that there are business opportunities within their major?

2. To what extent do students have an interest in innovating new products or services?

3. What is the level and extent of interest in taking either entrepreneurship courses, minors, certificates or majors?

We conducted our study among all students enrolled in courses during the fall of 2008 at Texas Tech University. We developed and refined a questionnaire and we posted it on TechAnnounce (An official email announcement/communication method for the TTU community.) and announced it to the population of students enrolled in fall classes via an e-mail message. The purpose of TechAnnounce is to facilitate the communication of University business and events. All messages are posted at http://techannounce.ttu.edu, and it is for TTU use only.

The questionnaire contained 17 statements designed to measure interest in entrepreneurship and characteristics of entrepreneurs to which students responded to statements such as "I have ideas for new technologies" using a 5-point scale $(1=$ strongly disagree, $5=$ strongly agree). The questionnaire also included specific demographic descriptors, such as academic major and minor, academic rank, and gender.

\section{Results}

In total, 81 students enrolled in fall courses responded to the TechAnnounce e-mail and completed surveys during a 4-week period in November 2008. With respect to academic major and gender, we judged that the sample was representative of the university's student population during the regular academic year.

Using a 5-point Likert scale, respondents indicated their level of agreement with the statement regarding business opportunities: "There are many opportunities to create new businesses in my major" (figure 3). A total of $23.5 \%$ (19 of 81) chose strongly agree with respect to the creation of new businesses, and $34.5 \%$ (28 of 81 ) chose somewhat agree. By combining the strongly agree and somewhat agree responses, we determined that a total of $58 \%$ (47 of 81) of students indicated that there are many opportunities to create new businesses in their majors. 
Figure 3: Opportunities VS Colleges

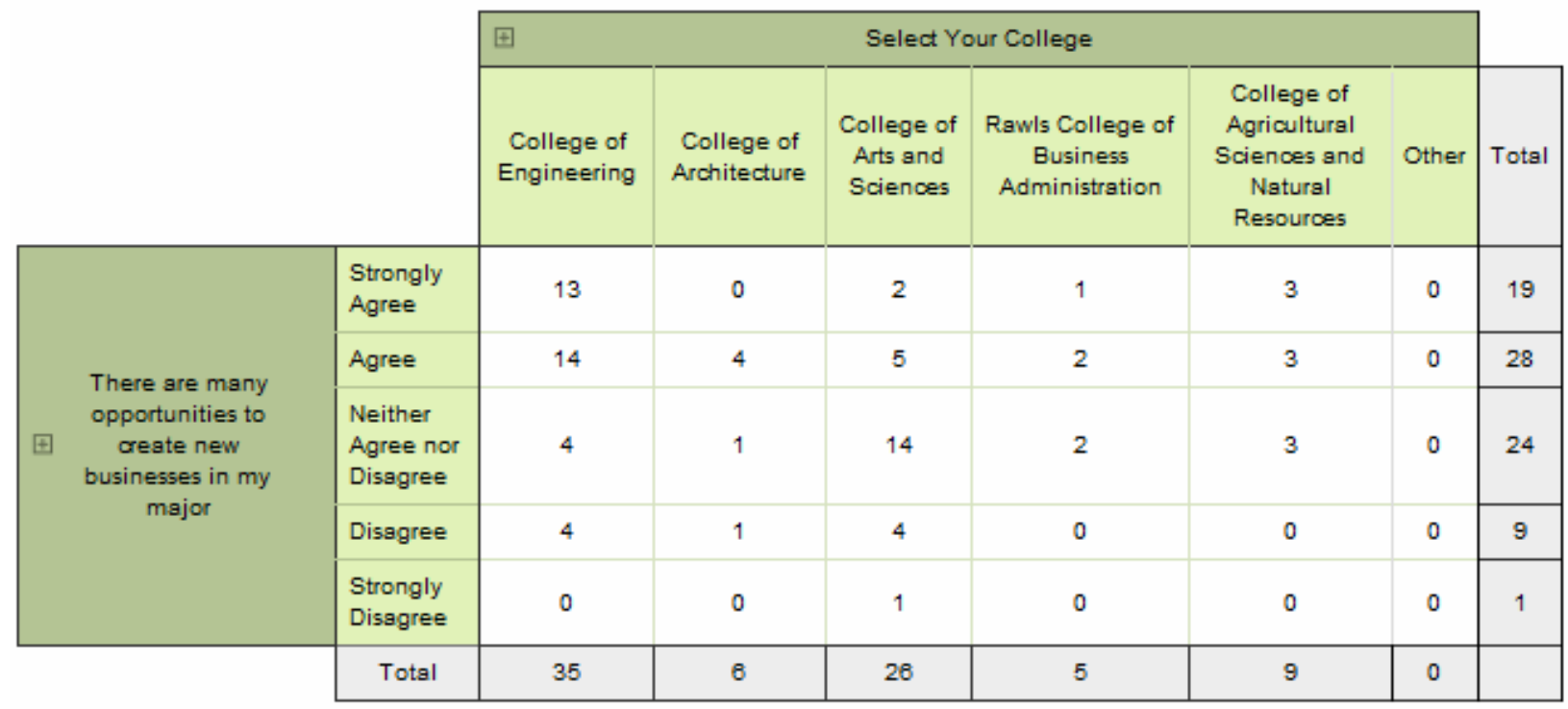

Then, with the statement new products or improving existing ones: "I like to tinker with ideas for new products or improving existing ones" (figure 4). A total of 23.5\% (19 of 81) chose strongly agree with respect of having ideas for new products or improving existing ones, and 48.2\% (39 of 81) chose somewhat agree. By combining the strongly agree and somewhat agree responses, we determined that a total of $71.6 \%$ (58 of 81 ) of students indicated that there are many TTU students are constantly thinking about the creation of new products and business opportunities.

Figure 4: Colleges VS New ideas

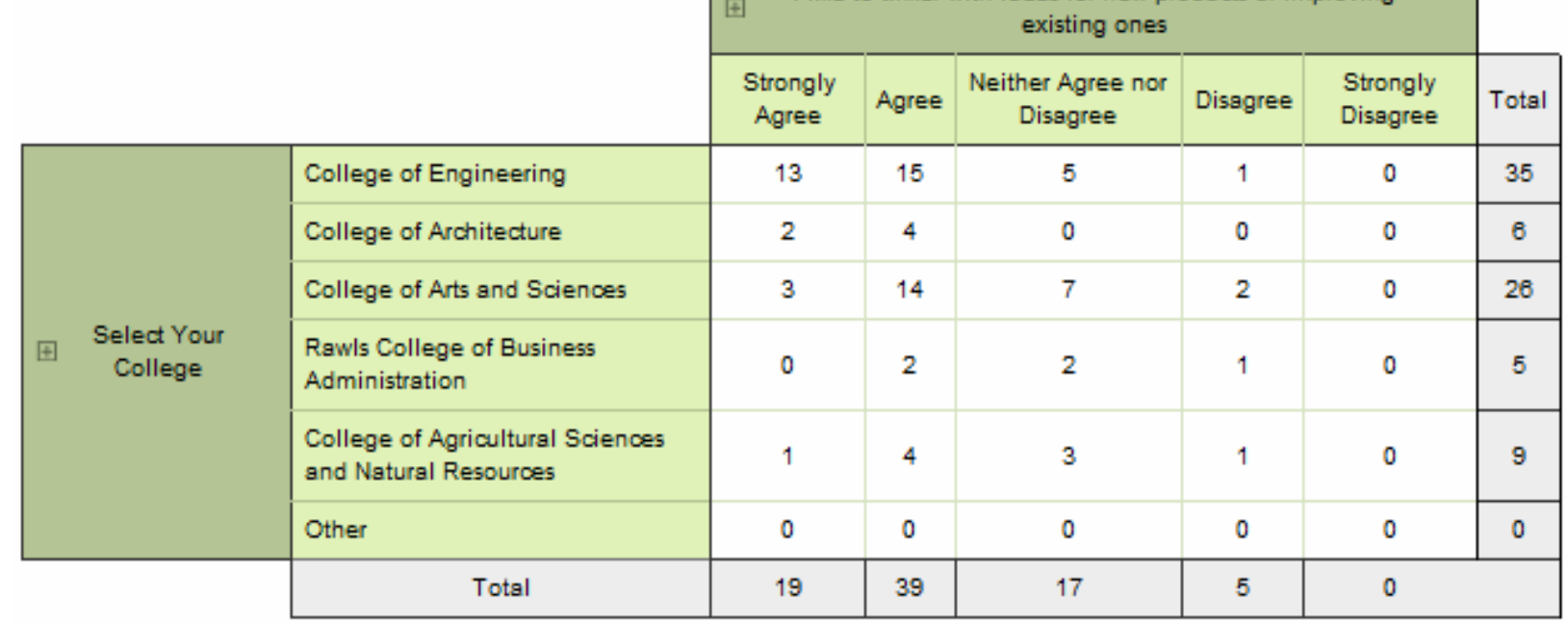


Finally, we wanted to identify the student's interest on entrepreneurship programs. Students were asked, "If a new Technology Entrepreneurship Program is offered to provide the basic skills to create new business opportunities, I would be most interested in." Response options included (a) a major (30 credit hours); (b) a minor (21 credit hours); (c) Certificate (12 credit hours); (d) 1-3 courses, and (e) not interested (See figure 5).

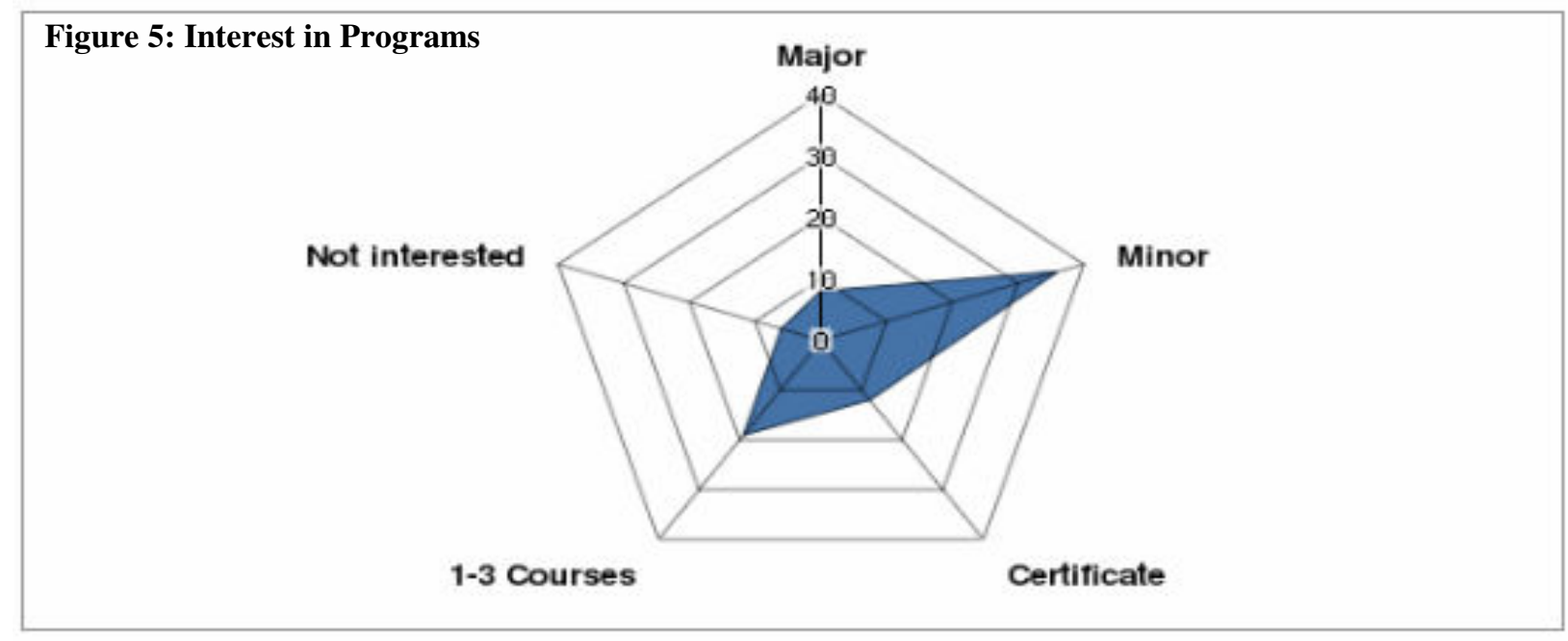

As we can see in figure 5, students have an inclination to a minor program rather that a certificate or majors. However, a Graduate Certificate in Technology Entrepreneurship should be the logic next level needed to promote entrepreneurial spirit across student population. These results give us the opportunity to understand and recognize what TTU student population think about entrepreneurship programs and their entrepreneurial spirit.

\section{Discussion}

Entrepreneurship is more than the mere creation of business. Although that is certainly an important facet, it is not the complete picture. The characteristics of seeking opportunities, taking risks beyond security, and having the tenacity to push an idea through to reality combine into a special perspective that permeates entrepreneurs.

Even though many graduate students do not plan on start a new business, this GTEC will provide the tools to create a business-oriented perspective for those non-business students, and a technology perspective to those in business school. Understanding all the business phases of a technological project can give our graduate students a significant advantage. 
These are important characteristics in engineers, scientists, and business entrepreneurs that make possible the creation of business opportunities. This paper presents an interdisciplinary graduate certificate that will provide an integrated a model where basically every college, faculty, and students get involved. This innovative Wind Turbine Model $^{\mathrm{TM}}$ provides a simple perspective to what we want to achieve. This original model integrates students with different backgrounds into one objective, the development of concepts in leadership, innovation, creativity, and the exploration of new business opportunities.

The findings illustrate that a considerable percentage of students aspire toward entrepreneurship, regardless of their academic discipline. From the data we gathered, it appears that the entrepreneurial spirit is alive across TTU interdisciplinary population (e.g., Architecture, Arts and Sciences, Engineering, Agricultural Sciences and Natural Resources, and Business). Indeed, these findings imply that entrepreneurial aspirations, as well as the perceived need for entrepreneurship training or education, may be most fervent not only in the business school.

Also, to ensure proper representation of the student population during the regular academic year, it would be better to proceed with the study during the spring semester of 2009 .

When we combined the strongly agree and somewhat-agree responses in the survey, we realized that the student's entrepreneurial spirit across campus is alive. Students understand that there are many opportunities to create new businesses in their majors. Also, it reflects that they are constantly thinking about the creation of new products and business opportunities.

\section{Implications for Future Research}

Since very little research has been done that explores interdisciplinary GTEC, we encourage professors, and students from different colleges to start analyzing what has been done at their departments and what is taking place concerning entrepreneurship. Further research involving all the colleges at TTU and their respectively feedback would be fruitful to reach accurate results.

An extensive survey and a statistical analysis will be conducted by the Entrepreneurial Engineering Excellence Research Group in the Department of Industrial Engineering at TTU to measure interest in entrepreneurship and entrepreneurial characteristics among business and nonbusiness students across the university student's population. These results will provide a measure of overall interest in entrepreneurship across TTU.

Since this paper reflects an interdisciplinary GTEC plan, further analysis will be needed. We still collecting information statistical information for the survey, so we can have a bigger population to implement a statistical analysis. However, we have already started the process to implement the Graduate Certificate in Technology Entrepreneurship at Texas Tech University. We hope to have this certificate fully implemented by the fall semester of 2010 . 


\section{References}

1. Texas Tech University, Office of Official Publications. (2007). Undergraduate and Graduate TTU Catalog 200708.

2. Drucker, P.R. (1985). "Innovation and entrepreneurship" New York: Harper \& Row.

3. Solomon, G.T., S. Duffy and A. Tarabishy (2002). "The state of entrepreneurship education in the United States: A nationwide survey and analysis”. International Journal of Entrepreneurship Education, (1), pp. 65-86.

4. Besterfield-Sacre M., M. Lovell, J. McGourty, L. Shuman, and H. Wolfe (2002). "An interdisciplinary certificate in product realization: Meeting the challenges of industry and the engineering criteria" $32^{\text {nd }}$ ASEE/IEEE frontiers in education, Nov 6-9, Boston, MA

5. Sagie, A., and D. Elizur. (1999). "Achievement motive and entrepreneurial orientation: A structural analysis". Journal of Organizational Behavior, 20, 375-387.

6. Silvernagel C. and Richard R. Schultz (2004). "Building Cross-Campus Partnerships in Product Development andEntrepreneurship Education" Education that Works: The NCIIA 8th Annual Meeting, pp. 257-264.

7. Envick B.R.,,Thomas Madison and H. Richard Priesmeyer (2002). "An interdisciplinary approach to Entrepreneurship education: The cross-course project model" Proceedings of the Academy of Free Enterprise Education, Volume 7, Number 2

8. Ford Ralph M., Jana G. Goodrich \& Robert S. Weissbach (2004). "A multidisciplinary business and engineering course in product development and entrepreneurship". 34th ASEE/IEEE Frontiers in Education Conference, October 20 - 23, Savannah, GA

9. Nichols Steven P. \& Neal E. Armstrong (2003), "Engineering entrepreneurship: does entrepreneurship have a role in engineering education?" IEEE Antennas and Propogation Magazine, Vol. 45, No. 1, pp. 134-138.

10. Vickers, Ken (2007). "Graduate certificates in entrepreneurism? A survey of existing programs as a guide to creating new graduate certificate programs". ASEE Annual Conference, Honolulu.

11. Stiesdal H. (1998), “The Bonus-Info 1998 newsletter” Bonus Energy A/S. Retrieved January 15, 2009, "http://www.scribd.com/doc/9220212/BONUS-Wind-Turbine-How-a-Wind-Turbine-Works-The-TheoryDesign-of-Modern-Wind-Turbines" 
Appendix: Description of courses that are part of the graduate certificate

\section{Turbine Course:}

MGT 5373. Entrepreneurship: Prerequisite: MGT 5376, ACCT5401, and MKT 5360 or consent of instructor. It develops the new value creation skills and modes of thinking necessary for creating actionable opportunities in a variety of socioeconomic settings.

\section{Leading Blade:}

IE 5331. Theoretical Studies in Advanced Industrial Engineering Topics (Technological Entrepreneurship): Prerequisite: Consent of instructor and departmental approval. Individual theoretical study of advanced topic selected on the basis of departmental recommendation.

\section{Elective Blade:}

IE 5321 Decision Theory: Prerequisite: Consent of instructor. Philosophy, theory, and practice of management; decision theory and social responsibility.

IE 5323 The Engineering Management Environment: Management of research and development; the legal, financial, and professional interrelationships of engineers and their environment in relation to the modern production organization.

IE 5324 Advanced Economics of Systems: Prerequisite: I E 3301, equivalent, or consent of instructor. Design analysis and sensitivity of complex economic systems with evaluation of economic system performance measures and modeling.

IE 532. Productivity and Performance Improvement in Organizations: Productivity and performance improvement (including efficiency, effectiveness, quality, QWL, innovation, profitability, and budget ability theories, techniques, analysis, and applications for industrial systems.

IE 5329 Project Management: Technical, organizational, and personnel project management examination including planning, estimating, budgeting, scheduling, resources management, control. Risk analysis and management using software for project performance evaluation.

MGT 5378 Managing the Family Enterprise: Prerequisite: Previous experience with or in a family business is encouraged; or with permission of instructor. Strategic, management, or business issues involved in running family firms. Emphasis is on entrepreneurial family firms.

MGT 5379 Entrepreneurial Discovery: Prerequisite: MGT 5373 or permission of instructor. Further develops opportunity creation skills through understanding the entrepreneurial discovery process, to prepare for real-world opportunity recognition applications. 
MGT 5381 Managing Innovation and Change: Prerequisite: MGT 5371. This course focuses on understanding organization innovation and change and applying this knowledge to managing innovation and change processes.

MGT 5383 International Management: Prerequisite: MGT 5371. Comparative analysis of domestic, international, and multinational business operations, and the significance for organization and management.

\section{Home-College ENT Blade*}

ARCH 5302. Product Design Workshop: Introduction to the design and executed construction of a prototypical piece of furniture or other design product using an architectural design process.

ARCH 5383. Urban Land Development: The land conversion process including feasibility analysis market and merchandising targets, site selection design construction and financial analysis. Landuse controls, planning, and environmental constraints.

ECO 5320 Managerial Economics: Prerequisite: Consent of instructor. The application of economic analysis to the problems of private firms and public institutions. Emphasis on quantitative tools of analysis.

ECO 5332 Advanced International Finance: Prerequisite: Advanced graduate standing and consent of instructor. Advanced study of theory, problems, and policies associated with the international monetary system.

ESS 5321 Financial Management in Sport: Financial concepts and issues related to the sport industry, including methods and sources of revenue acquisition, financial analysis techniques, and economic impact.

ESS 5322 Management of Sport and Athletics: Methods of organizing and administering sport and athletic programs. Study of staff, program, budget, health and safety, facilities, publicity, history, duties of an athletic director, and national, state, and local controls.

ESS 5329 Sport Event Management: The study of management principles and procedures specific to the design, operation, and implementation of sporting events.

STAT 5370 Decision Theory: Prerequisite: MATH 4343 or STAT 5329 or consent of instructor. Game theory, statistical decision, Bayesian statistics.

AAEC 5312 Agribusiness Analysis: Prerequisite: AAEC 3315. Application of economic theory and methods to management problems of the business firms in the food and fiber sector. F.

AAEC 5315 Property Appraisal: Factors governing land prices, valuation. Appraisal for use, sale, lending, condemnation, estate settlement, taxation. Not open to students with AAEC 4303 or equivalent. F. 
AAEC 5316 International Agricultural Trade: Economic theory dealing with the international movement of goods, services, and capital; welfare and distributional aspects of trade; and policy issues in international agricultural trade. S.

AAEC 5318 Finance and the Agribusiness Sector: Prerequisite: FIN 5320. Applications of financial theory for the agribusiness sector. Risk, capital structure, business structure, investment analysis.

ANSC 5310 Advanced Quality Control and Management in Feed Manufacturing: Scientific principles and practices of quality control and management of feed manufacturing with respect to their effects on animal performance.

FDSC 5310 Food Sanitation Management: Food-borne pathogens and their control in a foodservice and retail setting. Topics include sanitation, food hygiene, FDA Model Food Code, and HACCP. Provides certification in applied food service sanitation management.

NRM 5311 Wildlife Conservation and Management: An examination of conservation principles and management practices enhancing wildlife populations. Not open to biological science majors.

* IE 5321- IE 5323- IE 5324- IE 5325- IE 5329 are also part of this blade. 